\title{
Kajian Pengaruh Fraksi Volume Serat Akibat Perlakuan Alkali Terhadap Ketangguhan Impak Komposit Limbah Serat Aren-Polyester
}

\author{
Wijoyo*, Achmad Nurhidayat ${ }^{\star \star}$ dan Catur Purnomo*** \\ ${ }^{*},{ }^{* *},{ }^{* * *}$ Dosen Jurusan Teknik Mesin, Fakultas Teknik, Universitas Surakarta \\ JI. Raya Palur Km. 5 Surakarta Tepl./Fax. 0271825117 \\ E-mail : joyowi@yahoo.co.id
}

\begin{abstract}
The purpose of this study is to investigate the influence of fiber volume fraction of the impact strength of palm fiber-unsaturated polyester composite and investigate the mechanism of fracture caused by impact loads.

This research material is palm fiber (Arenga pinnata), unsaturated polyester matrix yukalac BQTN-EX 157 type, hardener metyl etyl ketone peroxide (MEKPO), alkali solution $(\mathrm{NaOH})$ and $\mathrm{H}_{2} \mathrm{O}$. Testing with Charpy impact tester, impact test specimens prepared according to standard test ASTM D-5942. While the macro picture is used for the analysis of the fracture.

The results showed that the most optimum impact toughness of palm fiber-polyester composite reached $0.011 \mathrm{~J} / \mathrm{mm}^{2}$ on volume fraction (Vf) $40 \%$. While the interaction characteristics of palm-fiber bond strength polyester showed matrix cracking behavior of failure on volume fraction (Vf) $10 \%$ to $30 \%$, and fiber pull out the volume fraction (Vf) $40 \%$ and $50 \%$, the same fracture behavior between the matrix and fibers in volume fraction (Vf) $40 \%$ indicates that fiber and matrix has a strong bonding interaction.
\end{abstract}

Keywords: Palm fiber, Polyester, Toughness, Volume fraction

\section{Pendahuluan}

Material komposit serat alam merupakan material alternatif yang sangat menguntungkan bila dibandingkan dengan material monolitik lainnya, dimana dewasa ini telah berkembang dengan cepat, dan semakin mendapatkan perhatian serius dari para ilmuwan dan para insinyur yang bergelut dalam bidang ilmu bahan (material science), dan mekanika bahan (mechanics of material). Sebagai sumber utama yang dapat diperbaharui, serat-serat lignocellulosic yang berasal dari struktur jaringan tumbuhan akan memainkan peranan utama dalam pengembangan perubahan $k e$ arah penggunaan bahan alam yang berbasis ekonomi sebagai konsekuensi dari Kyoto Protocol terhadap perubahan iklim global (UN FCC 1997). Pemanfaatan serat alam baik dari segi teknis maupun sebagai produk pertanian non-pangan telah dikembangkan sejak lama. Misalnya sebagai serat selulosa dalam industri tekstil dan bubuk kertas tetap menjadi komoditi utama dalam industri produk non-pangan. Pemasaran serat alam seperti flax, hemp, jute dan sisal mengalami penurunan yang sangat substansial semenjak dikembangkannya serat sintetis WO II dalam industri tekstil (FAO statistics). Meskipun demikian, pemanfaatan serat alam masih terjaga dan sejumlah pemanfaatan baru dipersiapkan untuk serat alam.
Menurut Hadi (2000) bahan komposit serat tediri atas serat-serat yang diikat oleh matriks. Bahan komposit serat ini juga terdiri atas dua macam, yaitu serat panjang (continuos fiber) dan serat pendek (short fiber atau whisker). Bahan komposit serat sangat efisien dalam menerima beban, karena tugas tersebut dilimpahkan ke serat. Seratlah yang terutama bertugas menerima beban. Oleh karena itu, bahan komposit serat sangat kuat dan kaku bila dibebani searah serat, sebaliknya sangat lemah bila dibebani dalam arah tegak lurus serat. Adapun gambar komposit serat sesuai Gambar 1.

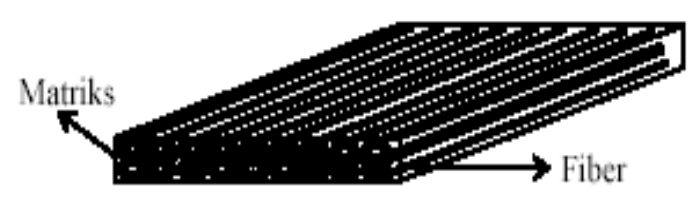

Gambar 1. Komposit serat

Ketersediaan limbah serat aren (Arenga Pinnata) saat ini hanya dibiarkan hingga membusuk atau dibakar setelah mengering. Sebelum tahun 2000, limbah ini pernah dipakai sebagai bahan kompos oleh Dr. Supriyadi. Namun, kelanjutan pembuatan kompos tersebut sudah tidak lagi dilakukan karena nilai jualnya rendah dan kurang diminati oleh masyarakat pedesaan. Padahal, kandungan serat dalam 
limbah tersebut mencapai di atas $80 \%$. Hal ini sangat potensial digunakan sebagai penguat komposit serat alam yang ramah lingkungan. Studi eksperimen pemanfatan serat alam ini juga sekaligus memperkaya daftar potensi tanaman serat alam di Indonesia sebagai penguat komposit. Sedangkan matrik perekat yang biasa digunakan dalam rekayasa panel komposit adalah bahan polimer thermosetting, dalam penelitian ini dipilih matrik unsaturated polyester yukalac 157 BQTN-EX karena banyak digunakan untuk aplikasi komposit pada dunia industri dengan pertimbangan harga relatif murah, waktu curing cepat, warna jernih, kestabilan dimensional baik dan mudah penanganannya.

Pramono, C (2008) melakukan penelitian pada komposit serat enceng gondok (eichornia crassipes) dengan matrik unsaturated polyester yukalac tipe 157 BQTN-EX. Hasil pengujian menunjukkan bahwa tegangan tarik tebesar pada serat non perlakuan $27.397 \mathrm{~N} / \mathrm{mm}^{2}$ namun elongasi pada serat non perlakuan tersebut menunjukkan nilai yang terendah yaitu $0.857 \%$. Sedangkan hasil pengujian kompatibilitas menunjukkan tegangan interfacial tertinggi terdapat pada spesimen perlakuan perendaman etanol kadar $10 \%$ sebesar $0.020 \mathrm{~N} / \mathrm{mm}^{2}$ dan nilai elongasi sebesar $1.999 \%$. Bentuk patahan menunjukkan patahan yang berbentuk tak beraturan seperti gerigi dan semakin ke ujung meruncing, sedangkan akibat pengujian kompatibilitas menunjukkan patahan yang sebagian matrik ikut tercabut pada ujung matrik yang menunjukkan adanya kecocokan serat terhadap matrik.

Pramono, C dan Nurhidayat, A (2010) mengemukakan bahwa kekuatan tarik optimum komposit serat aren-unsaturated polyester tercapai pada fraksi volume $40 \%$ yaitu sebesar $32,225 \mathrm{MPa}$.

Taurista, dkk (2006) mengemukakan bahwa serat bambu dengan data mekanis pengujian didapatkan bahwa kekuatan tarik aktual terbesar dimiliki oleh komposit dengan lebar serat $5 \mathrm{~mm}$ dengan nilai $\sigma$ aktual sebesar 16,806 $\mathrm{Kg} / \mathrm{mm}^{2}$. Regangan tarik terbesar dimiliki komposit dengan lebar serat $5 \mathrm{~mm}$ dengan nilai aktual sebesar 0,012. Sedangkan modulus elastisitas tarik terbesar dimiliki komposit dengan lebar serat $5 \mathrm{~mm}$ dengan nilai sebesar 1421,129 $\mathrm{kg} / \mathrm{mm}^{2}$. Kekuatan bending terbesar dimiliki oleh komposit dengan lebar serat $5 \mathrm{~mm}$ dengan nilai $17,60533 \mathrm{~kg} / \mathrm{mm}^{2}$. Hasil tersebut sudah memenuhi syarat untuk aplikasi material kulit kapal, sesuai standar BKI (Biro Klasifikasi Indonesia).

Wijoyo (2009) mengemukakan bahwa hasil penelitian pada komposit serat aren dengan matrik urea formaldehide adalah kekuatan tarik komposit meningkat secara linier seiring dengan penambahan kandungan serat aren dari 11,84 gram (fraksi berat serat 17,67\%) hingga 26,5 gram (fraksi berat serat $41,41 \%$ ), yaitu kekuatan tertinggi adalah pada fraksi berat serat $41,41 \%$ sebesar 26,79 MPa, seperti pada Gambar 2 .

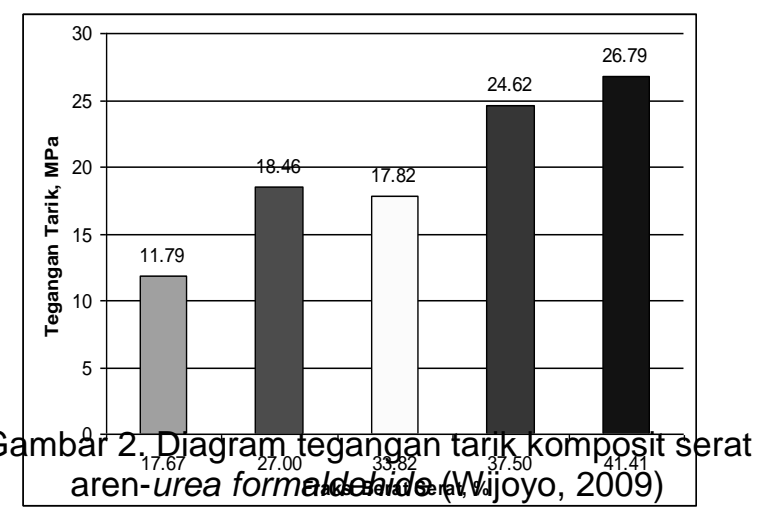

Wijoyo dan Diharjo (2009) mengemukakan bahwa hasil riset ketangguhan impak komposit sandwich GFRP dengan core PU menunjukkan bahwa besarnya energi serap yang dapat ditahan oleh komposit sandwich GFRP dengan core PUF $20 \mathrm{~mm}$ (55.22 J) adalah 68.51\% di atas energi serap komposit sandwich GFRP dengan core PUF $10 \mathrm{~mm}$ (32.77 J). Kekuatan (ketangguhan) impak komposit sandwich GFRP 3 layerPUF10mm-GFRP 1 layer $\left(0.0201 \mathrm{~J} / \mathrm{mm}^{2}\right)$ lebih besar dibandingkan dengan kekuatan bending komposit sandwich GFRP 3 layer - PUF 20 mm GFRP 1 layer $\left(0.0176 \mathrm{~J} / \mathrm{mm}^{2}\right)$. Semakin tebal core polyurethane semakin besar energi serapnya (energi patah), namun kekuatan impaknya semakin menurun.

Wijoyo dan Sugiyanto (2010)

mengemukakan bahwa hasil riset pada komposit serat nanas-polyester menunjukkan kekuatan tarik yang optimum pada perlakuan alkali $30 \%$ selama 2 jam yaitu sebesar 1023,37 MPa dan elongasi 6,266\%. Sedangkan kompatibilitasnya terbaik pada serat yang mengalami perlakuan 4 jam baik dengan larutan alkali maupun dengan etanol.

Penelitian ini betujuan menyelidiki pengaruh fraksi volume serat terhadap kekuatan impak komposit serat aren-unsaturated polyester serta menyelidiki mekanisme patahan yang terjadi akibat beban impak.

\section{Metode Penelitian \\ Bahan dan Alat Penelitian}

Bahan-bahan yang diperlukan dalam pembuatan spesimen uji impak yaitu serat aren (Arenga Pinnata), matrik Unsaturated Polyester yukalac tipe 157 BQTN-EX, hardener metyl etyl keton peroksida (MEKPO), larutan alkali $(\mathrm{NaOH})$ dan $\mathrm{H}_{2} \mathrm{O}$. Peralatan utama yang digunakan dalam penelitian ini adalah alat uji impak Charpy dan timbangan elektronik HR 200 ND, oven, jangka 
sorong, kamera digital dan peralatan pendukung lainnya.

\section{Teknik Pembersihan/Pengolahan dan Perlakuan Serat}

Tahap awal serat aren (Arenga Pinnata) dicuci pada bak pencuci hingga bersih. Setelah kotoran larut di air, maka serat diangkat dengan strimin yang sudah diletakkan dibawah adukan serat sebelumnya. Serat yang sudah bersih kemudian direndam dengan larutan $\mathrm{NaOH} 10 \%$ selama 4 jam. Serat kemudian di cuci kembali dengan air mengalir guna menetralisir $\mathrm{NaOH}$. Serat tersebut kemudian dikeringkan secara alami hingga kadar air relatif konstan selama minimal satu minggu. Pengeringan serat dilakukan secara alami di dalam ruangan tanpa sinar matahari langsung selama 3 hari hingga kadar air berkisar 8-10\%, karena pada kondisi ini serat memiliki kekuatan tertinggi.

\section{Teknik Pembuatan Spesimen Uji}

Spesimen uji impak dibuat menurut standar uji ASTM D-5942 dengan dimensi panjang, lebar dan tebal berturut-turut adalah $62,7 \mathrm{~mm}, 20 \mathrm{~mm}$ dan $5 \mathrm{~mm}$, seperti pada Gambar 3. Spesimen uji dibuat dengan variasi vraksi volume serat $\left(V_{f}\right)=$ $10 \%, 20 \%, 30 \%$, $40 \%$, dan $50 \%$.

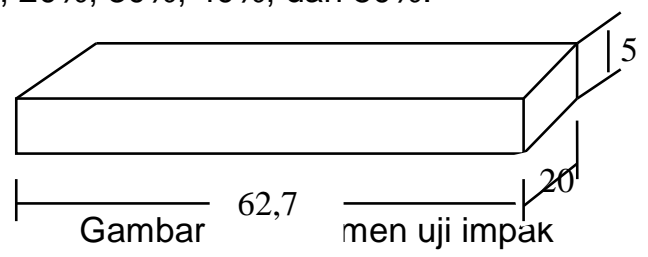

\section{Hasil Dan Pembahasan \\ Ketangguhan Impak Komposit}

Pengujian impak komposit serat arenpolyester adalah pengujian mekanis untuk mengetahui energi serap dan ketangguhan menahan beban kejut.

Besarnya energi serap komposit serat aren-polyester dengan fraksi volume $\left(V_{f}\right)$ 10\%, 20\%, 30\%, 40\%, dan 50\% adalah 0,354 J, 0,462 $\mathrm{J}, 0,532 \mathrm{~J}, 0,776 \mathrm{~J}$, dan $0,633 \mathrm{~J}$, seperti ditunjukkan pada Gambar 4. Hasil tersebut menunjukkan bahwa semakin besar fraksi volume serat maka energi serap komposit semakin meningkat. Peningkatan energi serap ini sesuai dengan hukum ROM yaitu akibat penambahan serat, komposit akan mampu meningkatkan sifat mekanisnya. Namun, setelah melampaui nilai optimum akan cenderung drop, hal ini dikarenakan ikatan antara matrik dengan serat yang rendah, sehingga menurunkan energi serap. Energi serap yang paling optimum pada komposit aren-polyester ini mencapai $0,776 \mathrm{~J}$ pada fraksi volume $\left(V_{f}\right) 40 \%$.

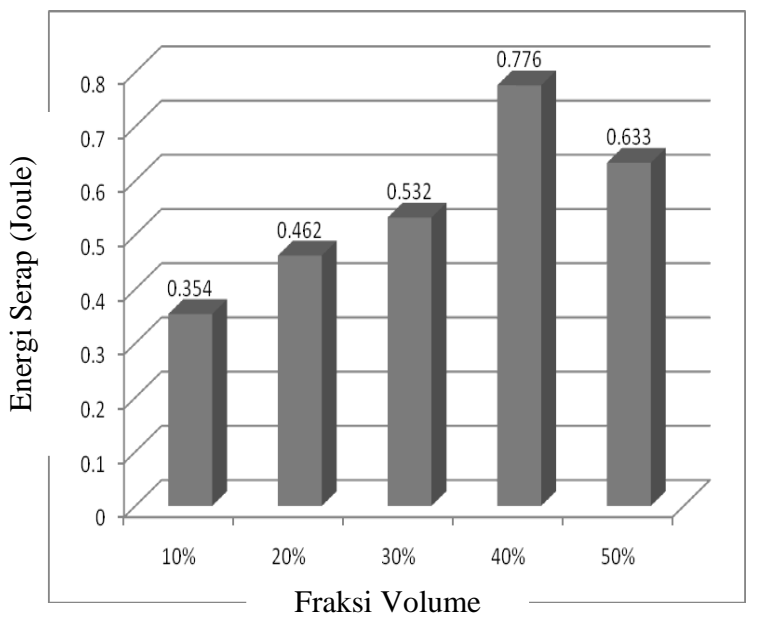

Gambar 4. Diagram energi serap komposit serat aren-polyester

Ketangguhan impak komposit arenpolyester dengan fraksi volume $\left(V_{f}\right) 10 \%, 20 \%$, $30 \%$, 40\%, dan $50 \%$ adalah $0,006 \mathrm{~J} / \mathrm{mm}^{2}, 0,008$ $\mathrm{J} / \mathrm{mm}^{2}, 0,010 \mathrm{~J} / \mathrm{mm}^{2}, 0,012 \mathrm{~J} / \mathrm{mm}^{2}$, dan 0,010 $\mathrm{J} / \mathrm{mm}^{2}$, seperti ditunjukkan pada Gambar 5. Hasil ketangguhan impak tersebut menunjukkan bahwa semakin besar fraksi volume serat maka ketangguhan impak komposit juga semakin meningkat. Ketangguhan impak yang paling optimum pada komposit serat aren-polyester ini mencapai $0,012 \mathrm{~J} / \mathrm{mm}^{2}$ pada fraksi volume $\left(V_{f}\right)$ $40 \%$. Hal ini menunjukkan bahwa pengaruh besar fraksi volume $\left(V_{f}\right)$ yang lebih besar sampai $40 \%$ memungkinkan mampu mendistribusikan beban pada komposit, sehingga ketangguhan komposit lebih tinggi. Namun, setelah melampaui nilai optimum akan cenderung drop, hal ini dikarenakan ikatan antara matrik dengan serat menurun, sehingga menurunkan ketangguhan impaknya.

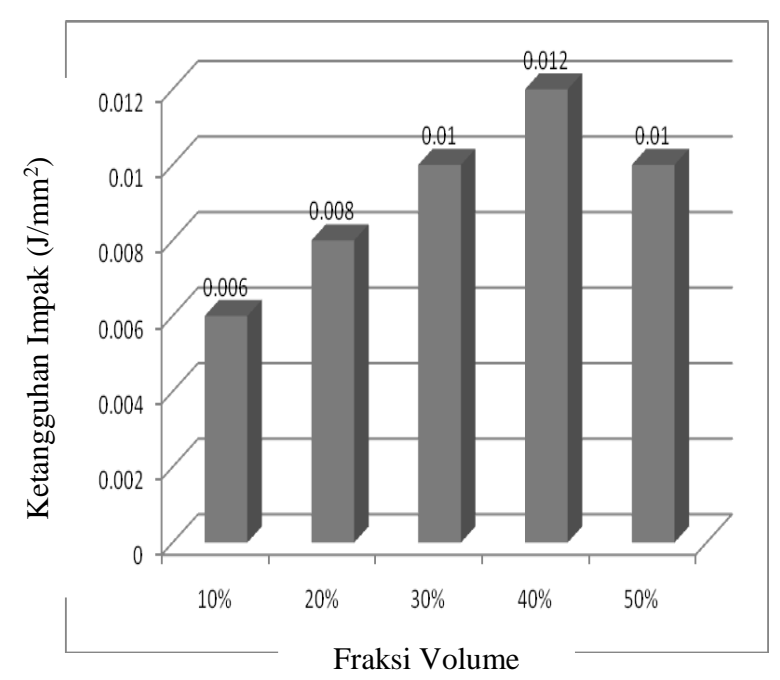


Gambar 6. Penampang patahan uji impak

Gambar 5. Diagram ketangguhan impak komposit serat aren-polyester

\section{Analisis Penampang Patahan}

Beban impak yang diterima komposit didistribusikan langsung pada serat dan matrik. Kegagalan yang terjadi pada komposit menunjukkan adanya fiber pull out yang lebih banyak pada komposit yang memiliki kandungan serat yang lebih besar, hal ini berdasar penampang patahan yang terjadi. Penampang patahan komposit menunjukkan perilaku kegagalan matrix cracking dan fiber pull out.

Dari penampang patahan uji impak pada komposit dengan fraksi volume $\left(V_{f}\right) 10 \%, 20 \%$, $30 \%$ kegagalan cenderung dikarenakan akibat kegagalan matrik terlebih dahulu, namun pada fraksi volume $\left(V_{f}\right) \quad 40 \%$ kegagalan menunjukkan adanya penguatan dari serat yaitu ditandai dengan patahnya serat dan matrik yang cenderung bersamaan. Sedangkan pada fraksi volume $\left(V_{f}\right) 50 \%$ kegagalan didominasi akibat komposisi matrik yang kurang sehingga penguatan seakan hanya berasal dari serat saja, jika dilihat dari penampang patahan menunjukkan fenomena yang semakin banyaknya fiber pull out. Secara umum, penampang patahan menunjukkan adanya fiber pull out yang lebih banyak pada komposit yang memiliki kandungan serat lebih besar. Penampang patahan komposit menunjukkan perilaku kegagalan matrix cracking pada fraksi volume $\left(V_{f}\right) 10 \%$ sampai $30 \%$ dan fiber pull out pada fraksi volume $\left(V_{f}\right) 40 \%$ dan $50 \%$, seperti ditunjukkan pada Gambar 6 . Perilaku patahan yang bersamaan antara matrik dan serat pada fraksi volume $\left(V_{f}\right) \quad 40 \%$ mengindikasikan bahwa serat dan matrik memiliki interaksi ikatan yang kuat.

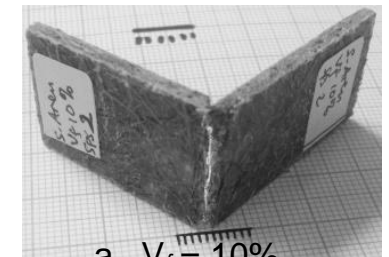

a. $V_{f}=10 \%$

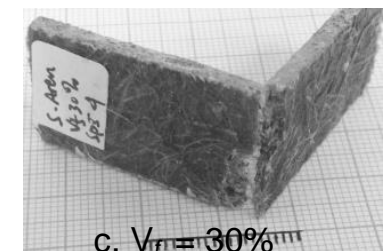

C. $V_{\text {If }}=130 \%$
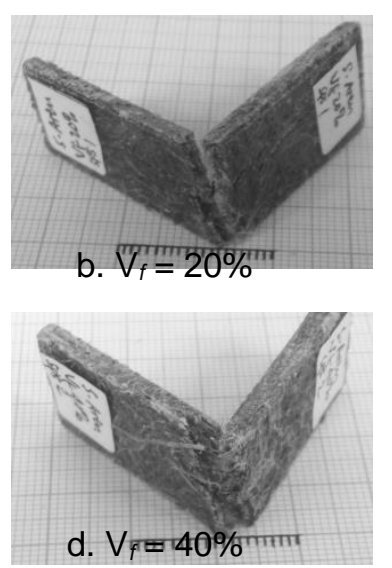

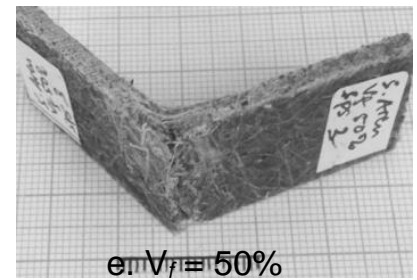

\section{Kesimpulan}

Dari hasil pembahasan tersebut di atas dapat disimpulkan :

1. Ketangguhan impak yang paling optimum pada komposit serat aren-polyester mencapai $0,012 \mathrm{~J} / \mathrm{mm}^{2}$ pada fraksi volume $\left(V_{f}\right) 40 \%$.

2. Karakteristik interaksi kekuatan ikatan serat aren-polyester menunjukkan perilaku kegagalan matrix cracking pada fraksi volume $\left(V_{f}\right) 10 \%$ sampai $30 \%$ dan fiber pull out pada fraksi volume $\left(V_{f}\right) 40 \%$ dan $50 \%$, perilaku patahan yang bersamaan antara matrik dan serat pada fraksi volume $\left(V_{f}\right) \quad 40 \%$ mengindikasikan bahwa serat dan matrik memiliki interaksi ikatan yang kuat. 


\section{Daftar Pustaka}

Anonim, 1998. "Annual Book ASTM Standart", USA.

Diharjo K., dan Ngafwan, 2004. "Pengaruh kepadatan Core PVC Terhadap Peningkatan Kekuatan bending dan Impak Komposit sandwich Serat Gelas", Penelitian Dosen Muda, DIKTI, Jakarta.

Diharjo K., Dan Nurhidayat A., 2004. "Teknik Penguatan Komposit Serat Karung Plastik Berlubang", Penelitian Dosen Muda, DIKTI, Jakarta.

Diharjo K., Soekrisno, Triyono dan Abdullah G., 2002-2003. "Rancang bangun Dinding Kereta Api Dengan Komposit Sandwich Serat gelas", Penelitian Hibah Bersaing X, DIKTI, Jakarta.

George J., Janardhan R., Anand J.S., Bhagawan S.S., dan Thomas S., 1996. "Melt Rheological behavior os short Pineapple Fibre Reinforce Low Density Polythylene Composites", Journal of Polymer, Volume 37, No. 24, Gret Britain.

Gibson, O. F., 1994. "Principle of Composite Materials Mechanics", McGraw-Hill Inc., New York, USA.

Hadi, B.K, 2000, Mekanika Struktur Komposit, Direktorat Jendral Pendidikan Tinggi, Jakarta.

Jones, R. M., 1975. "Mechanics of Composite Materials", Scripta Book Company, Washington D.C., USA.

Karnani R., Krishnan M., dan Narayan R., 1987. "Biofibre Reinforce Polypropylene Composites", Reprinted from Polymer Engineering and Science, Vol. 37, No. 2.

Kaw A.K., 1997. "Mechanics of Composite Materials", CRC Press, New York.

Pramono, C. 2008."Pengaruh Larutan Alkali dan Etanol Terhadap Kekuatan Tarik Serat Enceng Gondok dan Kompatibilitas Serat
Enceng Gondok pada Matrik Unsaturated Polyester Yukalac tipe 157 BQTN-EX". Skripsi, Jurusan Teknik Mesin UNDIP, Semarang.

Pramono, C. dan Nurhidayat, A. 2010."Pengaruh Perlakuan Alkali Terhadap Kekuatan Tarik Komposit Serat Aren (Arenga Pinnata) dengan Matrik Unsaturated Polyester pada Berbagai Variasi Fraksi Volume”. PDM, Kopertis VI, Semarang.

Ray D., Sarkar B.K., Rana A.K., dan Bose N.R., 2001. "Effect of Alkali Treated Jute Fibres on Composites Properties", Bulletin of Materials Science, Vol. 24, No. 2.

Shackelford, 1992. "Introduction to Materials cience for Engineer", Third Edition, MacMillan Publishing Company, New York, USA.

Taurista, dkk.2006 "Komposit Laminat Bambu Serat Woven Sebagai Bahan Alternatif Pengganti Fiber Glass Pada Kulit KapalJurusan Teknik Material, Institut Teknologi Sepuluh Nopember, Surabaya.

Wijoyo, 2009, " Kajian Komprehensif Kekuatan Tarik Komposit Serat Aren (Arenga Pinnata) Dengan Matrik Resin Formaldehide", Simposium Surakarta.

Wijoyo dan Diharjo, 2009, " Analisa Kegagalan Impak Komposit Sandwich Serat Gelas Dengan Core Polyuretan", MechATronic AUB, Volume 4, hal. 42-51, Surakarta.

Wijoyo dan Diharjo, 2007, " Kajian Komprehensif Kinerja Bending Komposit Sandwich Serat Gelas Dengan Core Polyuretan", PDM, Dikti, Jakarta.

Wijoyo dan Sugiyanto, 2010, "Pengaruh Larutan Alkali dan Etanol Terhadap Kekuatan Tarik Serat Nanas dan Kompatibilitas pada Matrik Unsaturated Polyester", PDM, Kopertis VI, Semarang. 